\title{
Multiple Sulfatase Deficiency Disease
}

National Cancer Institute

\section{Source}

National Cancer Institute. Multiple Sulfatase Deficiency Disease. NCI Thesaurus. Code C84908.

A rare autosomal recessive lysosomal storage disease caused by mutations in SUMF1 gene. It is characterized by deficiency of all sulfatase enzymes. Signs and symptoms include neurologic damage, mental retardation, skeletal abnormalities, hepatosplenomegaly, and ichthyosis. 